\title{
Assessment of Muscular Activity and Postural Load During Coffee Harvesting Activities - A Case Study*
}

Evaluación de la carga muscular y postural de la actividad de recolección de café: caso de estudio

Received: April 2, 2019 | Accepted: September 17, 2019 | Published: February 24, 2020

\author{
Sebastián Peláez ${ }^{a}$ \\ Pontificia Universidad Javeriana, Bogotá, Colombia. \\ ORCID: 0000-0002-3399-9135 \\ Leonardo Quintana \\ Pontificia Universidad Javeriana, Bogotá, Colombia. \\ ORCID: 0000-0001-5625-0111
}

${ }^{*}$ Research article

a Corresponding author. Email: pelaezs@javeriana.edu.co

DOI: https://doi.org/10.11144/Javeriana.iyu24.amap

How to cite this article:

S. Peláez, and L. Quintana, "Assessment of muscular activity and postural load during coffee harvesting activities:

-a case study," Ing. Univ., vol. 24, 2020. https://doi.org/10.11144/Javeriana.iyu24.amap 


\section{Abstract}

Objective: The goal of this case study was to analyze and evaluate the posture, force and repetitive movement risks associated with manual coffee harvesting activities. Materials and Methods: A self-discomfort report was administered to 28 participants, of whom 4 volunteered for an evaluation of postural load on muscular activity using electromyography and electrogoniometry. Eight upper limb muscles and the kinematics of the wrist and upper arm of the dominant arm were assessed. Results: The results of the self-discomfort report showed a greater demand, from the harvester's perception, in areas such as the back, lower back, knees and feet during a period of one week of work. The outcomes of the muscular activity assessment showed that the extensor carpi ulnaris (ECR) was the muscle with the highest demand during the assessment. The dynamic activity of the muscle exceeded $20 \%$ of the maximum voluntary contraction (MVC), which classifies coffee harvesting as a threatening activity. The postural load on the body segments revealed that wrist deviation was critical due to an abnormal range of the wrists during the activity. Conclusions: It is necessary to improve the working conditions of the coffee harvesters.

Keywords: mechanical demand; manual harvesting; ergonomics

\section{Resumen}

Objetivo: Analizar y evaluar los riesgos de postura, fuerza y movimientos repetitivos asociados con las actividades manuales de recolección de café. Materiales y métodos: Autorreporte de incomodidad en 28 participantes, de los cuales 4 se ofrecieron como voluntarios para una evaluación de la carga postural sobre la actividad muscular mediante electromiografía y electrogoniometría. Se evaluaron 8 músculos de las extremidades superiores y la cinemática de la muñeca y la parte superior del brazo dominante. Resultados: Los resultados del autorreporte arrojaron que existe una mayor demanda, desde la percepción del recolector, en áreas como la espalda, la espalda baja, las rodillas y los pies durante un periodo de una semana de trabajo. Los resultados de la evaluación de la actividad muscular mostraron que el extensor cubital del carpo era el músculo con mayor demanda durante la evaluación. La actividad dinámica del músculo excedió el $20 \%$ de la contracción voluntaria máxima, que clasifica la cosecha de café como una actividad amenazante. La carga postural en los segmentos del cuerpo reveló que la desviación de la muñeca era crítica, debido a un rango anormal de las muñecas durante la actividad. Conclusiones: Es necesario mejorar las condiciones de trabajo de los recolectores de café.

Palabras clave: exigencia mecánica; recolección manual; ergonomía 


\section{Introduction}

Internationally, the agricultural sector is one of the most hazardous industries to the human body. Ergonomic risks and musculoskeletal disorders are important elements to consider in this sector [1], [2] due to the constant exposure of workers to them [1], [3]. In addition, according to Bureau of Labor Statistic (BLS) from 2014, 33.8 out of 10,000 workers had diseases related to musculoskeletal disorders. This is one of the highest disorder rates compared to other economic sectors [4].

Per the Labor Minister of Colombia, a combined $9.47 \%$ of labor illnesses were in agriculture, hunting and forestry. Additionally, illness data from the agricultural sector indicated a rate of 169.73 per 100,000 workers, and 37 qualified diseases corresponded to crop harvesting activities [5].

In 2014, the coffee crop represented $10 \%$ of the agricultural gross domestic product (GDP) in Colombia [6], and this is a motive for why this sector of agriculture was selected for the present research, which focuses on coffee harvesting tasks such as planting, cultivating and harvesting, which are activities that may be precursors to musculoskeletal disorders. These same factors have been included in past studies.

In Colombia, there are a few studies related to the working conditions in the agriculture sector (floriculture and coffee). In floriculture, researchers evaluated discomfort using surveys, a video analysis and direct measures of postural change and muscle activity. As a result, a patented prototype tool was designed for cutting, and it was evaluated in real conditions [7][10]. In coffee crop research, Oliveros and Sanz emphasized the advantages and disadvantages of mechanization in farming harvesting and the different tools that can help increase production [11].

On the other hand, international research in the agricultural sector has helped to identify factors that generate discomfort or fatigue in different parts of the body. These factors, including repetitive movements in awkward postures, extreme flexion and extension of the upper limb and lifting loads, have been evaluated using tools such as self-discomfort reports, Nordic questionnaires, observational analyses and direct measurements [3], [12]-[20].

The activity of Colombian coffee harvesters depends on the cropping stations; normally, the first harvest is from May to June, and the other harvest is from September to October. Additionally, the activity starts at 5 a.m. and continues until 5 p.m. On some farms, depending on the owners, food is provided for the harvesters. The cropping time depends on the size of the farm; normally, it will take them two or two and a half weeks to harvest a medium-sized farm (10 hectares). In Colombia, we have different topography conditions. The coffee is on the slopes of the mountains to the top of the mountains in the coffee triangle region, but normally, it is common to find the same conditions in other regions. 


\section{Methodology}

\section{Participants}

This research involved 28 volunteers from a farm in El Caimo, Quindio, Colombia, and only coffee harvesters participated. The demographic characteristics of the study population are shown in Table 1.

Table 1. Demographic data

\begin{tabular}{lr}
\hline \multicolumn{2}{c}{ Demographic Data } \\
\hline Men & $71 \%, \mathrm{n}=20$ \\
\hline Women & $29 \%, \mathrm{n}=8$ \\
\hline Age range & 18 to 73 \\
\hline Average Age & $38.2(\mathrm{SD}=14.6)$ \\
\hline Left Handed & $\mathrm{n}=28$ \\
\hline
\end{tabular}

Source: Authors own elaboration.

\section{Experimental design and procedure}

The experimental study analyzed the working conditions of coffee harvesting activities, considering the discomfort of the workers in their daily tasks. The self-discomfort report was administered for five days, three times during the working day [12]. A postural and muscular analysis was applied using electrogoniometry (EGM) and electromyography (EMG), while the worker performed the activity for 20 minutes. A video recording was made to analyze three specific postures: arms up, arms in a neutral position and arms down [8], [12].

\section{Condition of the body with respect to the task}

A self-report questionnaire of discomfort was administered at the beginning of the workday and at the middle and at the end of the day for each day on a 5-day workweek. The questionnaire consisted of a human figure, on which 16 parts of the human body were shown. The volunteer had to indicate the level of discomfort for each part of the body using a scale from 0 to 10 (Borg's Scale).

\section{Physical workload}

To analyze the mechanical demand associated with the postural load and muscular activity, it was necessary to take 20-minute measurements for each person at the beginning of the workday. The variables for postural load were flexion-extension and radial-ulnar deviations of the wrist (SG65, Biometrics Ltd, UK) and flexion and extension of the shoulder (SG150, Biometrics Ltd., UK). Signal tests were recorded at an initial reference position of $0^{\circ}$. The muscular activity was evaluated using EMG sensors (SX230, BioMetrics Ltd., UK) on the 
skin surface; they had a $10 \mathrm{~mm}$ diameter and were separated by a distance of $20 \mathrm{~mm}$ to preamplify the signal. The sensors were placed on the extensor carpi radialis (ECR), extensor carpi ulnaris (ECU), flexor carpi radialis (FCR), flexor carpi ulnaris (FCU), biceps (B), deltoid (D), extensor carpi radialis nondominant arm (ECR ND) and biceps nondominant arm (B ND). The correct positions of the sensors were determined by touch, according to the length of each muscle. Before the sensors were attached, the skin was cleansed following European standardized norms [21]-[23]. The signal was filtered with a bandwidth of 20-460 $\mathrm{Hz}$, and a band reject filter at $60 \mathrm{~Hz}$ was used to reduce the interference induced by the electric network (i.e., interference below $5 \mu \mathrm{V}$ and input impedance higher than $1000 \Omega$ ).

\section{Analysis of the results}

Depending on the number of reports greater than 3 on the level of discomfort reported by the volunteers, a color was assigned to classify the parts of the body that were identified as the most affected by the participants, as shown in Table 2 .

Table 2. Classification of the discomfort levels

\begin{tabular}{lll}
\hline COLOR & \multicolumn{1}{c}{ DISCOMFORT GREATER THAN 3 } & \multicolumn{1}{c}{ LEVEL } \\
\hline Blue & Less than 10\% & Very Low \\
\hline Green & From 10\% to 20\% & Low \\
\hline Orange & Less 20\% to 30\% & Medium \\
\hline Red & Equal or greater than 30\% & High \\
\hline
\end{tabular}

Source: Authors own elaboration.

The video recordings were analyzed using chronicle activities with the software Actogram Kronos 2 (France), where three arm postures were evaluated (arms up, arms in a neutral position and arms down). The ergonomic chronicle, actogram software and video, were used when the arms were in the different positions mentioned above.

Surface electromyography signals recorded in ASCII were processed using algorithms developed in MATLAB R 2013a (USA). The RMS signal (root mean square) was estimated from a moving window of $200 \mathrm{~ms}$ [8] and normalized with each muscle's MVC (Maximum Voluntary Contraction) record. P10 (static level), P50 (medium level) and P90 (dynamic level) were estimated using the amplitude probability distribution function (APDF).

Posture load information signals were processed by the data link software from the equipment (Biometrics Ltd., UK), recorded in ASCII (after filter) and measured in degrees. The angles of interest were associated with the corresponding APDF analyses, particularly emphasizing the averages and considering P10, P50 and P90 data. All records were processed and analyzed in SPSS 23.0 (IBM Corp. Released 2015. IBM SPSS Statistics for Windows, Version 23.0. Armonk, NY: IBM Corp.). Given the particular task, the study prioritized the body segments that fell out of the neutral ranges. 


\section{Results}

\section{Activity self-report}

At the beginning of the workday, the discomfort was very low, except for in the knees, in which the discomfort was medium. The other two reports from the same workday showed an increase in discomfort due to exposure to the working conditions and the fatigue of the human body. The last report from the working day indicated in high discomfort, as shown in Figure 1.

\section{Figure 1. Self discomfort report results}
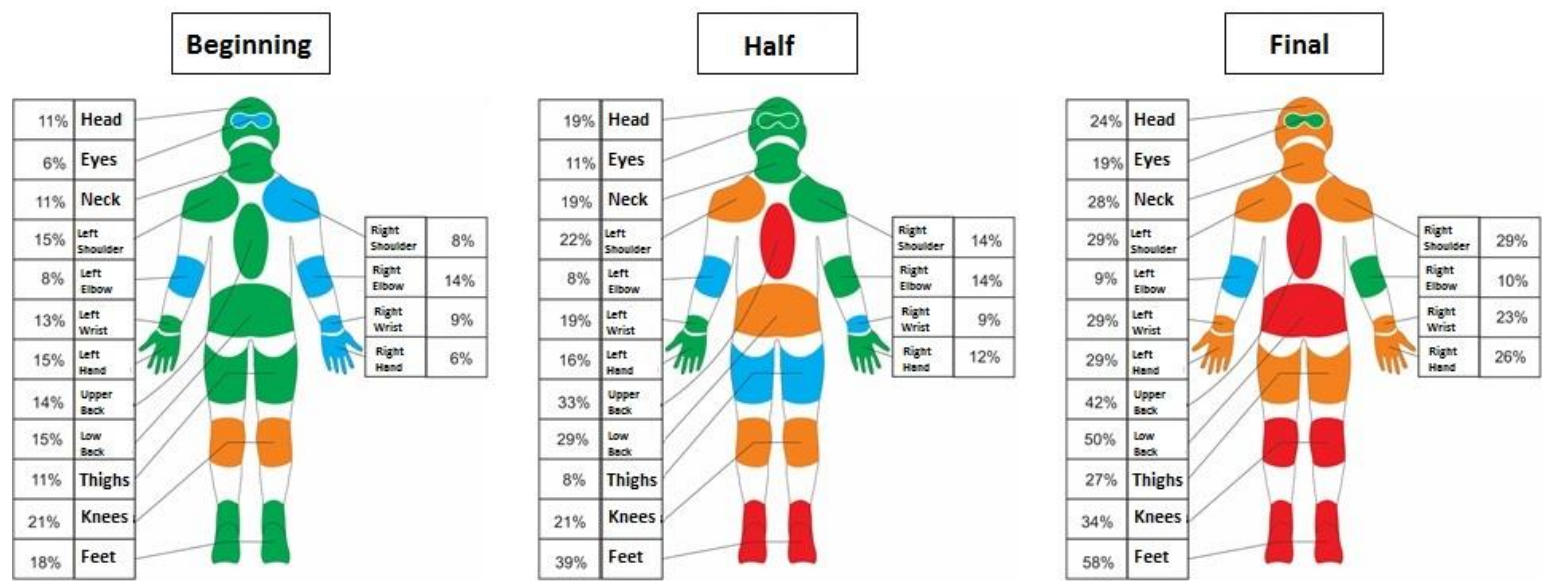

Source: Authors own elaboration.

\section{Postural load of the studied corporal segments}

The results from the corporal segments showed that during coffee harvesting activities, the flexion and extension of the wrist was in a neutral posture $72.2 \%$ of the time. The ulnar deviations of the wrist in the neutral range represented $37.2 \%$ of the time. However, the deviation presented out of the range was divided into two ranges: $15 \%$ of the ulnar deviation was greater than $40^{\circ}$, and $22.2 \%$ of the time in ulnar deviation was between $15^{\circ}$ and $40^{\circ}$. In addition, the radial deviation was out of the neutral range $36.7 \%$ of the time. Finally, shoulder flexion and extension were in the neutral range $84.7 \%$ of the time, and only $15.3 \%$ of the time did the work involve flexion greater than $90^{\circ}$ (Figure 2 and Table 3 ). 
Figure 2. Corporal segments: a) wrist deviation, b) wrist flexion and extension, and c) shoulder flexion and extension

a)

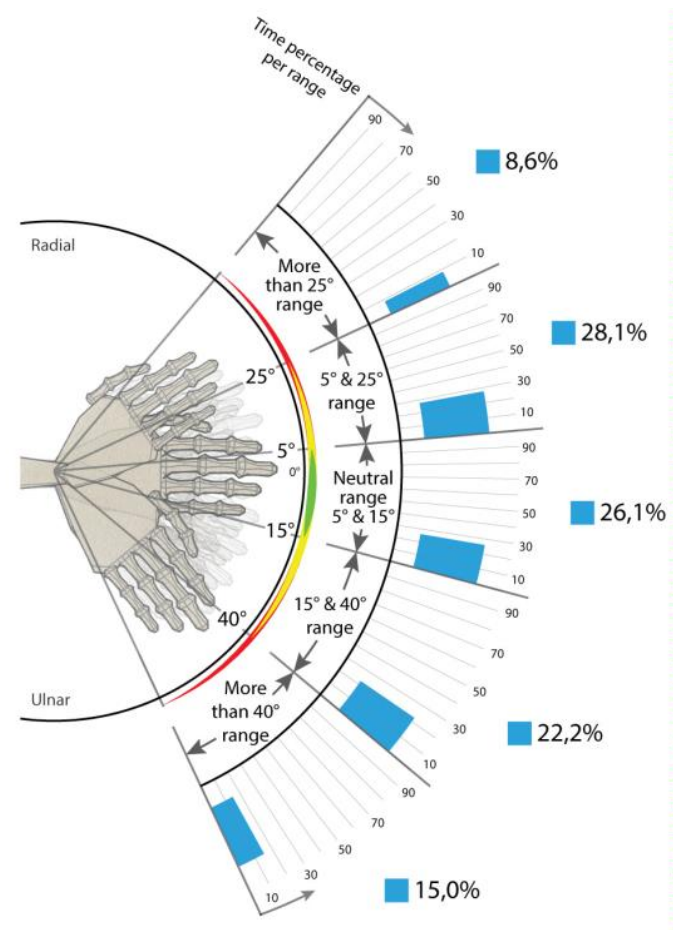

b)

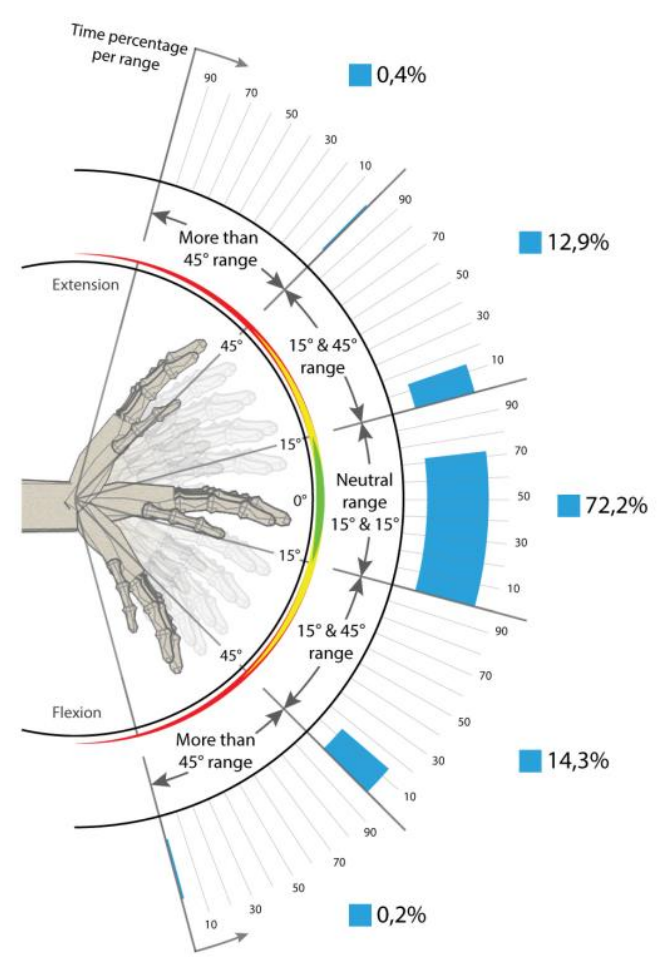

c)

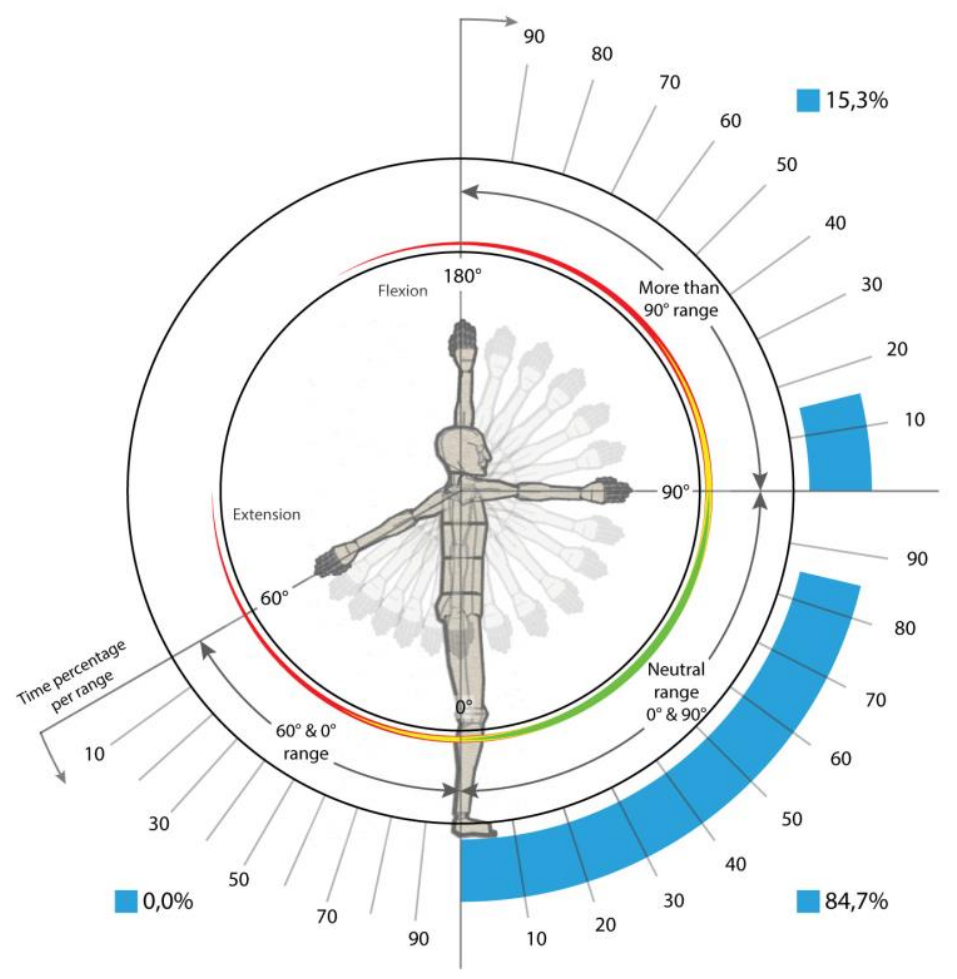

Source: Authors own elaboration. 
Table 3. Statistics of the GNM analysis

\begin{tabular}{|c|c|c|c|c|}
\hline \multicolumn{5}{|c|}{ Statistics } \\
\hline & & Wrist_Flex_Ext & Deviation_Rad_Uln & Shoulder_Flex_Ext \\
\hline \multirow{2}{*}{$\mathrm{N}$} & Valid & 248288 & 248288 & 248288 \\
\hline & Missing & 0 & 0 & 0 \\
\hline Mean & & 0,7304 & $-7,9352$ & $-20,5978$ \\
\hline Standard Error & & 0,02914 & ,05473 &, 03650 \\
\hline Median & & 1,6000 & $-3,7000$ & $-21,6000$ \\
\hline Mode & & 0,00 & 14,80 & 4,80 \\
\hline Std. Deviation & & 14,51926 & 27,27167 & 18,18870 \\
\hline Variance & & 210,809 & 743,744 & 330,829 \\
\hline Range & & 128,20 & 174,90 & 118,30 \\
\hline \multirow{3}{*}{ Percentiles } & 10 & $-17,7000$ & $-46,6000$ & $-44,6000$ \\
\hline & 50 & 1,6000 & $-3,7000$ & $-21,6000$ \\
\hline & 90 & 18,1000 & 23,1000 & 4,4000 \\
\hline
\end{tabular}

Source: Authors own elaboration.

\section{Muscular activity of the upper limbs}

The extensor carpi ulnaris was the most strained muscle in the static level (P10) with an MVC of $4.6 \%$ and a dynamic level (P90) of $29.3 \%$ of the MVC. This was the highest level reached during the neutral posture of the arms activity. In addition, it was identified that the biceps muscle of the nondominant arm had less muscle activity, as shown in Figure 3 and Table 4.

Figure 3. Maximum Voluntary Contraction by arm positions

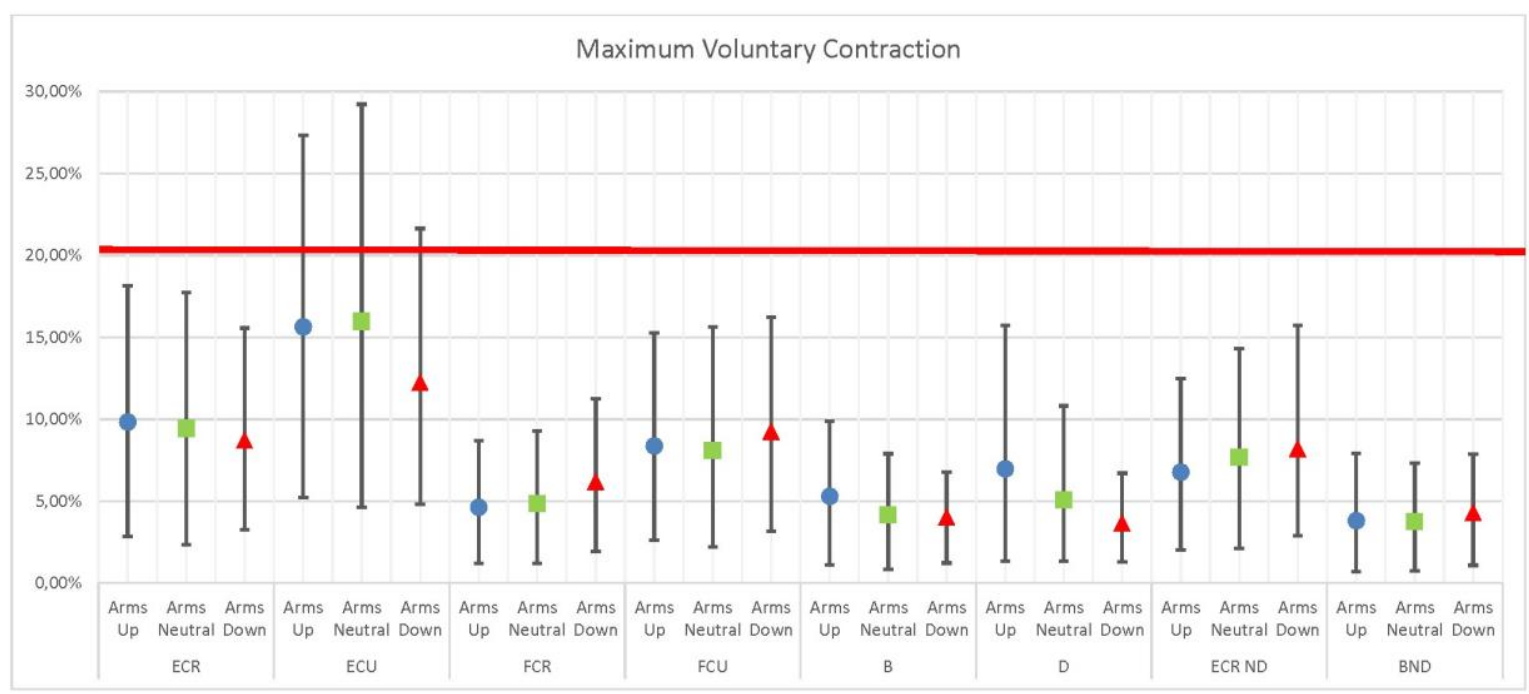

Source: Authors own elaboration. 
Table 4. EMG analysis (percent)

\begin{tabular}{|c|c|c|c|c|}
\hline & & & & \\
\hline & & Mean & Percentile 10 & Percentile 90 \\
\hline \multirow{3}{*}{ ECR } & Arms Up & 9.84 & 2.84 & 18.15 \\
\hline & Arms Neutral & 9.45 & 2.35 & 17.74 \\
\hline & Arms Down & 8.72 & 3.26 & 15.57 \\
\hline \multirow{3}{*}{ ECU } & Arms Up & 15.64 & 5.23 & 27.34 \\
\hline & Arms Neutral & 15.99 & 4.63 & 29.23 \\
\hline & Arms Down & 12.25 & 4.82 & 21.65 \\
\hline \multirow{3}{*}{ FCR } & Arms Up & 4.63 & 1.20 & 8.70 \\
\hline & Arms Neutral & 4.86 & 1.20 & 9.27 \\
\hline & Arms Down & 6.19 & 1.95 & 11.27 \\
\hline \multirow{3}{*}{ FCU } & Arms Up & 8.38 & 2.63 & 15.28 \\
\hline & Arms Neutral & 8.12 & 2.22 & 15.64 \\
\hline & Arms Down & 9.25 & 3.18 & 16.23 \\
\hline \multirow{3}{*}{ Biceps (B) } & Arms Up & 5.32 & 1.12 & 9.88 \\
\hline & Arms Neutral & 4.19 & 0.82 & 7.90 \\
\hline & Arms Down & 4.04 & 1.23 & 6.77 \\
\hline \multirow{3}{*}{ Deltoids (D) } & Arms Up & 6.98 & 1.33 & 15.73 \\
\hline & Arms Neutral & 5.11 & 1.34 & 10.82 \\
\hline & Arms Down & 3.66 & 1.28 & 6.71 \\
\hline \multirow{3}{*}{ ECR ND } & Arms Up & 6.79 & 2.03 & 12.49 \\
\hline & Arms Neutral & 7.69 & 2.12 & 14.30 \\
\hline & Arms Down & 8.19 & 2.88 & 15.73 \\
\hline \multirow{3}{*}{ BND } & Arms Up & 3.82 & 0.72 & 7.90 \\
\hline & Arms Neutral & 3.76 & 0.74 & 7.31 \\
\hline & Arms Down & 4.30 & 1.09 & 7.86 \\
\hline
\end{tabular}

Source: Authors own elaboration.

\section{Discussion}

In this case study, a methodology was established to determine the actual working conditions of the Colombian coffee sector, specifically during the manual coffee harvest, and the hope is that this study will serve as a starting point for future research. This case study also attempted to identify risk factors in manual coffee harvesting from the perspective of the worker and to measure muscle activity and study angular segments, in which the risk of injuring the extensor carpi ulnaris increases.

This case study only focused on the main activity in coffee harvesting; it was necessary to evaluate the tools and how those tools affected the human body. A similar study was conducted in Nicaragua [12], in which they had a basket instead of a bag. We also followed an experimental design used for flowering crops that was developed in Colombia [9]. 
It is also known that the risks will not disappear; rather, the risk will probably be transferred to another region of the body, and it is necessary to use different working methods or technology to improve the performance of the activity in different working conditions. Additionally, it is necessary to realize that in Colombia, the topography will affect the task conditions, and it will probably also affect human body postures. It is known that different kinds of mechanization will improve production [11], but it is necessary to evaluate that technology in Colombia.

\section{Conclusions}

In summary, this case study shows that throughout the workday, there is fatigue that is evident with a high level of discomfort, especially in the lower limbs, in which the workers reported the most distress. Nevertheless, after performing an evaluation of muscular exposure on workers, this study found that the upper limbs are the area that needs to be evaluated, especially in the case of the extensor carpi radialis (ECR), which contracted at $20 \%$ the MVC in the three positions studied. Additionally, the results of the body segment evaluation indicated that most of the time segments were in neutral ranges, except for the wrist, which deviated the combination of risk factors in the muscles and body movements could generate carpal tunnel syndrome over time.

For future research, it is necessary to analyze the lower limbs, including but not limited to the back, using electromyography and electrogonimetry and to determine the impact that the worker experiences due to the load from the collector bucket during manual coffee harvesting activities.

\section{Acknowledgements}

The purpose of this case study was to diagnosis the working conditions present in coffee harvesting activities in Quindío, Colombia. This research was part of a project developed within the Colciencias Young Researcher program and the Centro de Estudios de Ergonomía from the Pontificia Universidad Javeriana.

\section{References}

[1] F.A. Fathallah, "Musculoskeletal disorders in labor-intensive agriculture," Applied Ergonomics, pp. 738-743, 2010.

[2] S. Kirkhorn, G. Earle-Richardson, and R. Banks, "Ergonomic risks and musculoskeletal disorders in production agriculture: recommendations for effective research to practice," J. Agromed., pp. 281-299, 2010.

[3] J.M. Meyers, J. A. Miles, J. Faucett, I. Janowitx, D.G. Tejeda, V. Duraj, J. Kabashima, R. Smith, and E. Weber, "High risk task for musculoskeletal disorders in agricultural field work," Proceedings of the IEA 2000/ HFES 2000 Congress, pp. 616-619, 2000. 
[4] Bureau of Labor Statistics, "Nonfatal occupational injuries and illnesses requiring days away from work, 2014," Bureau of Labor Statistics, 2015.

[5] Ministerio del Trabajo de la República de Colombia, "Informe de actividades al Congreso 20132014," July 2014. [Online]. Available: http://www.mintrabajo.gov.co/atencion-alciudadano/transparencia/informe-enviado-al-congreso-de-la-republica.

[6] DANE, "Cuentas trimestrales-Colombia: product interno bruto (PIB). Cuarto trimestre de 2014," Boletín Técnico March 24, 2015. [Online]. Available: https://www.dane.gov.co/files/investigaciones/boletines/pib/bol_PIB_dem_IVtrime14_2.pdf [Accessed 5 Junio 2015].

[7] L.H. Barrero, C. Ceballos, R. Ellegast, J.A. Pulido, M. V. Monroy, S. Berrio, and L.A. Quintana, "A randomized intervention trial to reduce," Work, pp. 4971-4974, 2012.

[8] S. Berrio, L.H. Barrero, and L.A. Quintana, "A field experiment comparing mechanical demands of two pruners for flower cutting," Work, pp. 1342-1345, 2012.

[9] L.H. Barrero, J.A. Pulido, S. Berrio, M.V. Monroy, L.A. Quintana, C. Ceballos, U. HoehneHueckstaedt and R. Ellegast, "Physical workloads of the upper-extremity among workers of the Colombian flower industry," Am. J. Ind. Med., pp. 926-936, 2012.

[10] R.G. García-Cáceres, S. Felknor, J.E. Córdoba, J.P. Caballero, and L.H. Barrero, "Hand anthropometry of the Colombian floriculture workers of the Bogota plateau," Int. J. Ind. Ergonom. pp. 183-198, 2012.

[11] C.E. Oliveros-Tascón and J.R. Sanz-Uribe, "Ingeniería y café en Colombia," Rev. Ing., pp. 99-114, 2011.

[12] B.A. Silverstein, S.S. Bao, S. Russell, and K. Stewart, "Water and coffee: A systems approach to improving coffee harvesting work in Nicaragua," Human Factors, pp. 925-939, 2012.

[13] E. May, M. Scribani, S. Wyckoff, R. Buer, J. May, L. Wyckoff, and P. Jenkins, "An ergonomic assessment of the long handle blueberry harvesting rake,” Am. J. Ind. Med., pp. 1051-1059, 2012.

[14] B. Deros, N. Khamis, D. Mohamad, N. Kabilmiharbi, and D.D.I. Daruis, "Investigation of oil palm harvesters' postures using RULA analysis," 2014 IEEE Conference on Biomedical Engineering and Sciences, pp. 8-10, 2014.

[15] J. Wakula and K. Landau, "Ergonomic analysis of grapevine pruning and wine harvesting to define work and hand tools design requirements," Proceedings of the IEA 2000/ HFES 2000 Congress, pp. 365-368, 2000.

[16] A.E. Kato and F.A. Fathallah, "Ergonomic evaluation of California wingrape trellis systems," Proceedings of the Human Factora and Ergonomics Society 46th Annual Meeting, pp. 1162-1166, 2002.

[17] A.A. Ramahi and F.A. Fathallah, "Ergonomic evaluation of manual weeding practice and development of ergonomic solution," Proceedings of the Human Factors and Ergonomics Society 50th Annual Meeting 2006, pp. 1421-1425, 2006. 
[18] K. Davis and S. Kotowski, "Understanding the ergonomic risk for musculoskeletal disorders in the United States agricultural sector," Am. J. Ind. Med., pp. 501-511, 2007.

[19] Janowitz, D. G. Tejeda, J. A. Miles, V. Duraj, F. Fathallah, J. M. Meyers and J. Faucett, "Ergonomics interventions in the manual harvest of wine grapes," Proceeding of the IEA 2000/ HFES 2000 Congress, pp. 628-631, 2000.

[20] L. Kuta, J. Ciez and M. Mlotek, "Musculoskeletal load assessment of farmers during selected agricultural works," 6th International Conference on Applied Human Factors and Ergonomics and the Affiliated Conferences 2015, pp. 1696-1703, 2015.

[21] D.F. Stegeman and H.J. Hermens, "Standards for surface electromyography: the European project 'Surface'," SENIAM, pp. 108-112, 2007.

[22] Freriks, H. Hermens, C. Disselhorst-Klug, and G. Rau, "The recommendations for sensors and sensor placement procedures for surface Electromyography," in European Recommendations for Surface ElectroMyoGraphy - SENIAM 8, 1999.

[23] E. Delagi, J. Iazzetti, A. Perotto, and D. Morrison, Anatomical Guide for the Electromyographer: The Limbs and Trunk. Springfield, Illinois: Charles C. Thomas, 2011. 